\title{
Development of a Thin Layer Chromatography Method for Simultaneous Detection of Chloroquine, Azithromycin and Paracetamol in Counterfeit Tablets Used Against Covid-19
}

\author{
Faida Losa ${ }^{1}$, Timothy Mavanga Mabaya ${ }^{2}$, Jocelyn Mankulu Kakumba ${ }^{2},{ }^{3}$, Floribert Balazirhe $^{3}$, \\ Margaret Borive", Didi Mana Kialengila ${ }^{2}$, Jeremiah Mbinze Kindenge ${ }^{2, "}$ \\ ${ }^{1}$ Faculty of Medicine and Pharmaceutical Sciences, University of Kisangani, Kisangani, Democratic Republic of Congo \\ ${ }^{2}$ Faculty of Pharmaceutical Sciences, University of Kinshasa, Kinshasa, Democratic Republic of Congo \\ ${ }^{3}$ National Laboratory for Quality Control of Medicines, Public Health Ministry, Kinshasa, Democratic Republic of Congo
}

Email address:

jeremiembinze@gmail.com (J. M. Kindenge)

${ }^{*}$ Corresponding author

\section{To cite this article:}

Faida Losa, Timothy Mavanga Mabaya, Jocelyn Mankulu Kakumba, Michael Tambwe Ngoyi, Floribert Balazirhe, Margaret Borive, Didi Mana Kialengila, Jeremiah Mbinze Kindenge. Development of a Thin Layer Chromatography Method for Simultaneous Detection of Chloroquine, Azithromycin and Paracetamol in Counterfeit Tablets Used Against Covid-19. American Journal of Biomedical and Life Sciences. Vol. 8, No. 5, 2020, pp. 126-130. doi: 10.11648/j.ajbls.20200805.11

Received: July 9, 2020; Accepted: August 11, 2020; Published: August 31, 2020

\begin{abstract}
Corona Virus Disease 2019 (Covid-19) is an infectious disease manifested by fever, rate and difficulty in breathing that can lead to death. This pandemic has just paralyzed the world, causing more deaths amongst vulnerable people such as the elderly and people with immune problems. Several therapeutic agents are being tested for the treatment of Covid-19. The combination of Chloroquine, Azithromycin and Paracetamol is identified as a promising therapeutic candidate for Covid-19. To ensure the success of this therapy, medicines of high quality play a key role. Unfortunately, we are not totally spared from trafficking of poor quality pharmaceutical products. As a contribution to try solving this challenge, a convenient, rapid and simple Thin Layer Chromatography method (TLC), which permits the simultaneous determination of Chloroquine, Azithromycin and paracetamol has been developed. The Chromatographic separation was achieved on $60 \mathrm{~F}$ silica gel plate using a mixture of methanol-25\% ammonia (100:1.5, v/v). Iodine vapor and ultraviolet light at $254 \mathrm{~nm}$ were used for the visualization of the spots. The developed method was successfully applied to determine Chloroquine in 23 samples supposed to contain Chloroquine marketed in DRC. The results showed that $50 \%$ of the samples analyzed were non-compliant and should probably contain paracetamol instead of Chloroquine. It suggested that the optimized method could be used for routine quality assessment of Chloroquine, Azithromycin or Paracetamol in pharmaceutical preparations. Since counterfeiting of medicines continues to be a real problem in developing countries as demonstrated by this result, the development of simple and convenient analytical method that allowed the rapid analysis of medicines used in Covid-19 therapy is more than urgent.
\end{abstract}

Keywords: Thin Layer Chromatography, Simultaneous Detection, Counterfeit Tablets, Covid-19

\section{Introduction}

Coronavirus disease 2019 or Covid-19 (acronym for coronavirus disease 2019) is an emerging infectious disease like viral zoonosis caused by a strain of coronavirus called SARS-CoV-2 [1-5]. The most common symptoms are fever, cough, and breathing difficulty and more rarely, acute respiratory distress syndrome that may lead to death, especially amongst vulnerable people such as the elderly, hypertensive and diabetics patients. Another deadly complication is an exacerbated immune system response [1-3].

The disease appears in November 2019 in Wuhan, central China with unusual cases of pneumonia justifying severe containment measures in January 2020 [6-11]. In March 2020, the epidemic was reclassified as a pandemic by the World Health Organization (WHO) [4]. The Covid-19 pandemic 
spread rapidly to many other countries, which in turn took similar action in March, causing border closures, quarantining citizens and cancelling large gatherings such as concerts, schools and sporting events, as in the Democratic Republic of Congo (DRC).

Recommended measures to prevent Covid-19 include frequent hand washing using detergent or hydroalcoholic solution, face coverings, quarantine and social distancing. One of the therapeutic options is based on the rapid and correct management of clinical cases by administrating Chloroquine or Hydroxychloroquine combined with Azithromycin and Paracetamol in case of fever. For the researcher Didier Raoult, director of the Mediterranean Infection Institute in Marseille (France) and renowned specialist in infectious diseases, the possible effectiveness of Chloroquine is "excellent news" in the treatment of covid-19 [1-4].

Chloroquine is no longer used to prevent nor treat malaria in DRC because of the selection of plasmodium falciparum resistants isolates. As a consequence, Chloroquine is no longer available in public pharmacies. In response to this pandemic, the need for Chloroquine is increasing and counterfeiters are<smiles>CC(=O)Nc1ccc(O)cc1</smiles>

Paracetamol taking the opportunity of launching drugs of doubtful quality on the market, especially in developing countries where the quality system remains precarious. Such practice may totally compromise the success of this therapeutic option vis-a-vis Codiv-19. The WHO launched an alert on April 9, 2020 on the falsification of Chloroquine in certain African countries notably Cameroon, Niger and the DRC [12].

In this context, a simple analytical technique capable of simultaneously detecting these molecules (Chloroquine or Hydroxychloroquine, Azithromycin and Paracetamol) will be desirable in quality control laboratories that do not have advanced techniques such as High Performance Liquid Chromatography. Keeping this in mind, TLC which is low cost and less time consuming separative technique was developed in this study.

The aim of this study was mainly to develop a generic TLC method capable of simultaneously tracing these three active molecules with the goal of detecting them, highlighting falsifications or counterfeits and secondly demonstrate its applicability on some real samples collected in DRC<smiles>CCOCCOCCC(C)Nc1ccnc2cc(Cl)ccc12</smiles>

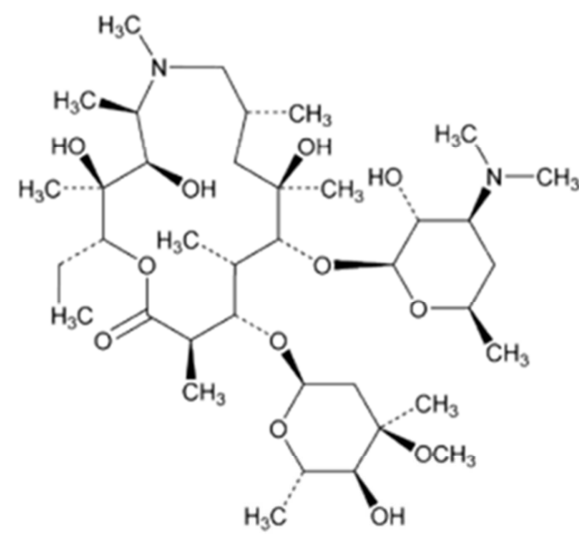

Azithromycin

Figure 1. Chemical structures of studied molecules.

\section{Experimental}

\subsection{Material}

The analysis was carried out using ready-to-use TLC plates, silica gel $60 \mathrm{~F}(20 \times 20 \mathrm{~cm})$ from the company Merck (Darmstadt, Germany). These plates were placed in glass vats. The electronic scale was of the GRAM FV-220C brand (IPESAGE S. A. S, France). A small amount of samples and standard were loaded to a starting point just above the bottom of TLC plate by using a $10 \mu \mathrm{L}$ micropipettes. The development of the TLC plate was carried out by using tank with filter paper liners and by leaving the tank to equilibrate before running the plates.

\subsection{Chemical Reagents}

Methanol, chloroform, 98\% acetic acid and 25\% ammonia for analysis were supplied by the Merck laboratory (Darmstadt, Germany). Chloroquine diphosphate (99.2\%) was supplied by Sigma - Aldrich (Antwerp, Belgium), Paracetamol (99.5\%) was supplied by Fagron N. V. (Waregem, Belgium). Azithromycin, corn starch, carboxymethylcellulose, 
magnesium stearate, talc, lactose and gelatin were supplied by the Laboratory for Quality Control of Medicines and Foodstuffs (Kinshasa, DRC).

\subsection{Methods}

\subsubsection{Preparation of Solutions}

1) Chloroquine phosphate solution $10 \mathrm{mg} \mathrm{mL}^{-1}$

$100 \mathrm{mg}$ of Chloroquine phosphate were dissolved in acetic acid and diluted to $10.0 \mathrm{~mL}$ with the same solvent.

2) Azithromycin solution $10 \mathrm{mg} \mathrm{mL}^{-1}$

$100 \mathrm{mg}$ of Azithromycin were dissolved in methanol and diluted to $10.0 \mathrm{~mL}$ with the same solvent.

3) Paracetamol solution $10 \mathrm{mg} \mathrm{mL}^{-1}$

$100 \mathrm{mg}$ of Paracetamol were dissolved in methanol and diluted to $10.0 \mathrm{~mL}$ with the same solvent.

4) Mixing solution

In a $10.0 \mathrm{~mL}$ volumetric flask $2.0 \mathrm{~mL}$ of Chloroquine phosphate solution, $2.0 \mathrm{~mL}$ of Azithromycin solution and 2.0 $\mathrm{mL}$ of Paracetamol solution were mixed.

5) Matrix blank solution

$100 \mathrm{mg}$ of corn starch, $100 \mathrm{mg}$ of carboxymethylcellulose, $100 \mathrm{mg}$ of magnesium stearate, $100 \mathrm{mg}$ of talc, $100 \mathrm{mg}$ lactose and $100 \mathrm{mg}$ of gelatin were successively dissolved in methanol and diluted to $100.0 \mathrm{~mL}$ with the same solvent. The mixture was filtered and the filtrate used for the study.

\subsubsection{Preparation of Mobile Phases}

Phase 1: $1.5 \mathrm{~mL}$ of $25 \%$ ammoniac and $100 \mathrm{~mL}$ of methanol were mixed in a $250 \mathrm{~mL}$ beaker

Phase 2: $1.5 \mathrm{~mL}$ of $25 \%$ ammoniac, $20 \mathrm{~mL}$ of methanol and $80 \mathrm{ml}$ of chloroform were mixed in a $250 \mathrm{~mL}$ beaker.
Phase 3: $80 \mathrm{~mL}$ of chloroform and $20 \mathrm{~mL}$ of methanol were mixed in a $250 \mathrm{~mL}$ beaker.

\subsubsection{Procedure}

After dissolution of the active ingredients, $10 \mu \mathrm{L}$ of each solution were deposited using a micropipette on the plate (previously activated) $2 \mathrm{~cm}$ from the bottom edge on the baseline. Each deposit was dried. The plate was then placed in the migration chamber containing the mobile phase. When the solvent front reached $1 \mathrm{~cm}$ from the upper edge of the plate, the chromatograms were removed, dried and viewed in the UV lamp at $254 \mathrm{~nm}$ and then using iodine steam.

\section{Results and Discussion}

\subsection{Method Developed}

To fully appreciate the separation of the three active ingredients, we used a random experiment plan which takes into account two factors, the concentration of active ingredient and the composition of the mobile phase. Table 1 gives the experimental domain. The experimental matrix and the results obtained during the experiments are depicted in Table 2. The minimum front gear is the difference between the closest front gears.

Table 1. Experimental domain.

\begin{tabular}{llll}
\hline Factors & Levels & & \\
\hline Concentration $(\mathbf{m g} / \mathbf{m L})$ & $\mathbf{0 . 1}$ & $\mathbf{1}$ & $\mathbf{1 0}$ \\
\hline Mobile phase & Phase 1 & Phase 2 & Phase 3 \\
\hline
\end{tabular}

Table 2. Experimental matrix.

\begin{tabular}{|c|c|c|c|c|c|c|}
\hline \multirow{2}{*}{ Trial } & \multirow{2}{*}{ Concentration (mg. $\mathrm{mL}^{-1}$ ) } & \multirow{2}{*}{ mobile Phase } & \multicolumn{3}{|c|}{ Retention factor } & \multirow{2}{*}{ minimal retention factor } \\
\hline & & & Chloroquine & Azithromycin & Paracetamol & \\
\hline 1 & 0.1 & Phase 1 & - & - & - & - \\
\hline 2 & 0.1 & Phase 3 & - & - & - & - \\
\hline 3 & 10.0 & Phase 3 & - & - & - & - \\
\hline 4 & 10.0 & Phase 2 & 0.35 & - & 0.76 & 0.41 \\
\hline 5 & 1.0 & Phase 3 & - & - & - & - \\
\hline 6 & 1.0 & Phase 2 & - & - & - & - \\
\hline 7 & 0.1 & Phase 2 & - & - & - & - \\
\hline 8 & 1.0 & Phase 1 & 0.35 & - & - & - \\
\hline 9 & 10.0 & Phase 1 & 0.35 & 0.51 & 0.75 & 0.16 \\
\hline
\end{tabular}

Legend: spot not detect.

Good separation of the three active pharmaceutical ingredients with the minimum retention factor value greater than zero was found with test 9 using phase 1, methanol-25\% ammoniac $(100: 1.5, \mathrm{v} / \mathrm{v})$ at a concentration of $10 \mathrm{mg} \mathrm{mL}^{-1}$ (Figure 1). The used mobile phase was selected because of its good polarity and its capacity to easily separate the medicines under analysis. Paracetamol was the most soluble $(\log \mathrm{P}=0.5)$, moved higher up the plate than Azithromycin $(\log \mathrm{P}=3.3)$ and Chloroquine ( $\log \mathrm{P}=4.6)$ [13]. Given three compounds which differ in solubility, the more soluble compound (Paracetamol) has a lower interaction with the TLC plate and is therefore more capable to move higher up the plate, resulting in a higher Rf value.
The analytes concentration played an important role, this is why the spots were clearly visible at high concentration such as $10 \mathrm{mg} \mathrm{mL}^{-1}$ which was not the case for $0.1 \mathrm{mg} \mathrm{mL}^{-1}$.

The minimum retention factor ( $\mathrm{Rf}$ ) value obtained was 0.16 or greater than 0.00 which means that the spots were well separated. After having saturated the chromatographic tank, 25 minutes were enough to obtain separation.

The developed method has been validated by demonstrating the selectivity as required by the French Societies in Pharmaceutical Sciences and Technologies [14-16]. There was no interference with the white matrix (without active ingredients) in the frontal relationships of the active molecules. 


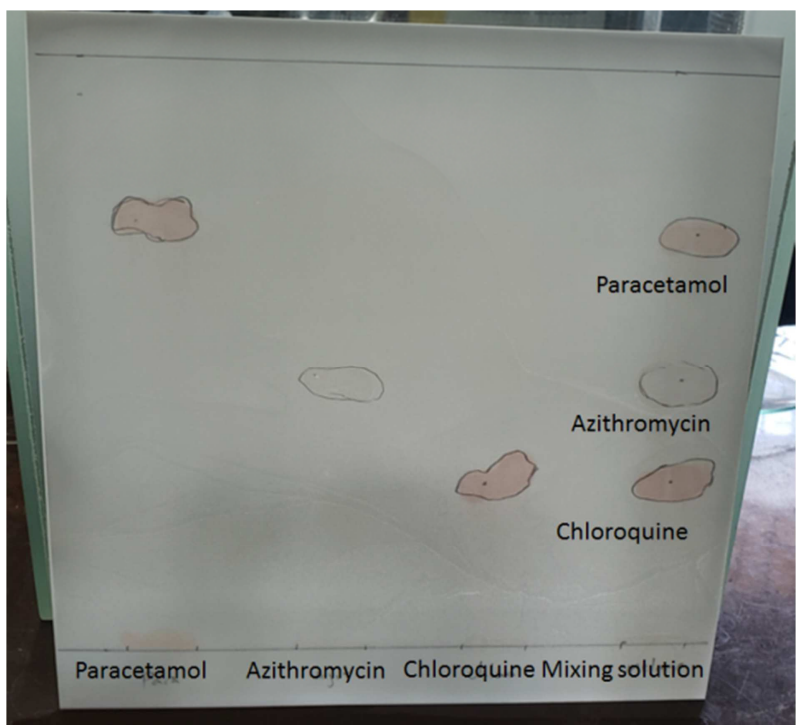

Figure 2. Chromatogram of separation of the three active ingredients by TLC.

\subsection{Method Application}

We applied the developed method by analyzing 23 samples marketed in Kinshasa (DRC) as shown in Table 3.

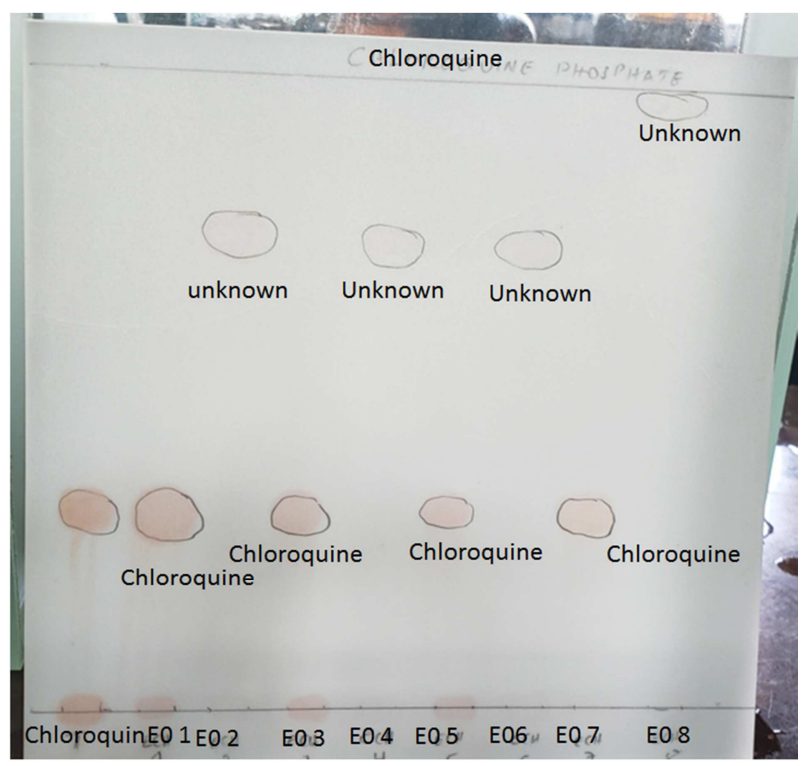

Figure 3. Analysis chromatogram of 8 samples based on chloroquine by TLC.

Table 3. Table depicting the samples characteristics.

\begin{tabular}{lllll}
\hline Codes & $\begin{array}{l}\text { Actif } \\
\text { ingredient }\end{array}$ & $\begin{array}{l}\text { Tablet } \\
\text { dosage }\end{array}$ & Batch number & $\begin{array}{l}\text { Country of } \\
\text { origin }\end{array}$ \\
\hline E01 & Chloroquine & $250 \mathrm{mg}$ & $00214 \mathrm{~L}$ & India \\
E02 & Chloroquine & $250 \mathrm{mg}$ & 028060 & Nigeria \\
E03 & Chloroquine & $250 \mathrm{mg}$ & 065622 & Belgium \\
E04 & Chloroquine & $250 \mathrm{mg}$ & EBT 2543 & Cameroon \\
E05 & Chloroquine & $250 \mathrm{mg}$ & EBT 172522 & Autral \\
E06 & Chloroquine & $250 \mathrm{mg}$ & 660 & China \\
E07 & Chloroquine & $100 \mathrm{mg}$ & $11220 \mathrm{~A}$ & India \\
E08 & Chloroquine & $250 \mathrm{mg}$ & HV1117 & No indiqued \\
E09 & Paracétamol & $500 \mathrm{mg}$ & 121103 & DRC \\
E10 & Paracétamol & $500 \mathrm{mg}$ & N9285 & Belgium \\
E11 & Paracétamol & $500 \mathrm{mg}$ & DAL 4Q09 & Belgium \\
E12 & Paracétamol & $500 \mathrm{mg}$ & N7689 & Belgium \\
\hline
\end{tabular}

\begin{tabular}{lllll}
\hline Codes & $\begin{array}{l}\text { Actif } \\
\text { ingredient }\end{array}$ & $\begin{array}{l}\text { Tablet } \\
\text { dosage }\end{array}$ & Batch number & $\begin{array}{l}\text { Country of } \\
\text { origin }\end{array}$ \\
\hline E13 & Paracétamol & $500 \mathrm{mg}$ & 5289 & French \\
E14 & Paracétamol & $500 \mathrm{mg}$ & Ji 20100007 & China \\
E15 & Paracétamol & $500 \mathrm{mg}$ & TG 00297 & DRC \\
E16 & Paracétamol & $500 \mathrm{mg}$ & TG 00276 & DRC \\
E17 & Azithromycin & $500 \mathrm{mg}$ & 1711219 & India \\
E18 & Azithromycin & $500 \mathrm{mg}$ & 831700 & India \\
E19 & Azithromycin & $500 \mathrm{mg}$ & ATAZM 8008 & India \\
E20 & Azithromycin & $500 \mathrm{mg}$ & $116578 \mathrm{~L}$ & India \\
E21 & Azithromycin & $500 \mathrm{mg}$ & $12202 \mathrm{BS}$ & India \\
E22 & Azithromycin & $500 \mathrm{mg}$ & $1 \mathrm{~A} 11002$ & India \\
E23 & Azithromycin & $500 \mathrm{mg}$ & 20223A1 & India \\
\hline
\end{tabular}

The overall analysis (identification of active molecules) carried out on the real samples showed that $4 / 23$ (or $17.4 \%$ ) of the products were counterfeit, especially $4 / 8$ or $50 \%$ of Chloroquine failed the identification test (Figure 2).

While $100 \%$ of Paracetamol and Azithromycin samples complied to the identification test. Counterfeiting medicines is very dangerous in the treatment of Covid-19 with risk of therapeutic failure and death for patients who are in critical situations.

The samples E02, E04 and E06 showed spots with Rf values closed to $\mathrm{Rf}$ value for Paracetamol (i.e. 0.75) while sample E08 showed a spot with an Rf value of 0.98 . HPLC-UV was used to identify the actives pharmaceutical ingredients in those samples (E02, E04 and E06) by comparing their UV spectra and retention times to those of Paracetamol reference substance. The UV spectra and retention times of those samples matched with the UV spectrum and retention time of Paracetamol reference solution (data not available in this study). This is to say that Paracetamol could be the probable product used in these samples (E02, E04 and E06) instead of Chloroquine. Extensive studies should confirm this observation. The counterfeiters have bet on the antipyretic product used against Covid-19 which costs less to earn money and treat only fever, so one could avoid using dangerous products like Anti-inflammatory No Steroids.

\section{Conclusion}

The main goal of this study was to develop a simple, rapid and convenient method for the simultaneous detection of Chloroquine, Azithromycin and Paracetamol used in the treatment of Covid-19 to fight against the circulation of counterfeit medicines during this pandemic.

A simple method using the $60 \mathrm{~F}$ silica gel plate, $20 \times 20 \mathrm{~cm}$ in size with a mobile phase composed of methanol-25\% ammonia (100:1.5, v/v) has been developed. The optimized method was applied to determine Chloroquine, Azithromycin and Paracetamol in real samples tablets. Using HPLC-UV, it was demonstrated that E02, E04 and E06 were probably containing Paracetamol instead of Chloroquine, which confirmed the WHO alert on counterfeit products found in the WHO African regions.

Counterfeit medicine is a threat in the fight against covid-19. We hope that this simple and rapid detection method will be 
helpful for a large number of laboratories in developing countries to ensure the quality of medicines currently used in the treatment of Covid-19.

In fine, the study results illustrated and highlighted the opportunity to use Thin Layer Chromatography which is low cost, less time consuming, less complicated separation technique and currently found in several laboratories, particularly in developing countries for the simultaneous analysis of Chloroquine, Azithromycin and Paracetamol.

\section{Acknowledgements}

The authors thank the National Laboratory for Quality Control of Medicines and Laboratory for Quality Control of Medicines and Foodstuffs and, the Pharmacy and Medicine department of the DRC Ministry of Public Health for the collaboration.

\section{References}

[1] Labidi, A. H., Un nouveau protocole pour un traitement potentiel des infections dues à Covid-19, 2020 (3), https://doi.org/10.31219/osf.io/dzhsy.

[2] Labidi, A. H., Un Nouveau Protocole Pour Un Traitement Potentiel Des Infections Dues À Covid-19.” OSF Preprints, 2020, 3

[3] Rolain JM, Colson P, Raoult D. Recycling of chloroquine and its hydroxyl analogue to face bacterial, fungal and viral infections in the 21 st century. Int J Antimicrob Agents. 2007, 30, pp297-308.

[4] OMS, « Nouveau coronavirus (COVID-19): conseils au grand public » [archive], sur who.int/fr/ (consulté le 8 Avril 2020).

[5] China's first confirmed Covid-19 case traced back to November 17» [archive], sur South China Morning Post, 13 mars 2020 (consulté le 8 Avril 2020).

[6] Brice Louvet, «Plusieurs dizaines de personnes frappées par un virus non identifié en Chine» [archive], sur SciencePost, 7 janvier 2020.

[7] Poissy J., Goutay J., Caplan M., Parmentier E., Duburcq T.,
Lassalle F.,, Jeanpierre E., Rauch A., Labreuche J. and Susen S., Pulmonary Embolism in Patients With COVID-19, Awareness of an Increased Prevalence, American Heart Association, 2020, 142, pp 184-186.

[8] Mehta P., McAuley D., Brown M., Sanchez E., Tattersall R. S., Manson J., COVID-19: consider cytokine storm syndromes and immunosuppression, Lancet., 2020, 28, pp 1033-1034.

[9] Lepira B. F., Mayamba Nlandu Y. Risassy Makulo J. R,. Kevaani, Lepira R, Kuezina Tonduangu D., Laniet Mangalaboyi J., Lenteur de propagation de la COVID-19 en Afrique subsaharienne: réalité ou sommet de l'iceberg ? Cas de la République Démocratique du Congo, Annales Africaines de Médecine, 2020, 13, pp 20-24.

[10] T. Rubin D., D. Feuerstein J., Wang A. Y., Cohen R. D., AGA Clinical Practice Update on Management of Inflammatory Bowel Disease During the COVID-19 Pandemic: Expert Commentary, Gastroenterology, 2020, 159, pp 350-357.

[11] Antunes Brito C., Gerardo Paiva J., Nunes Pimentel F., Santos Guimarães R., Ribeiro Moreira M, COVID-19 in patients with rheumatological diseases treated with anti-TNF, Annals of the Rheumatic Diseases, 2020, 1, pp 1-5.

[12] OMS, alerte produit médical $\mathrm{N}^{\circ} 4 / 2020$ : clhoroquine, falsififiée circulant dans la région Afrique de l'OMS, Avril, 2020.

[13] Clarke's Analysis of Drugs and Poisons, 2006.

[14] Hubert Ph., Nguyen-Huu J. J., Boulanger B., Chapuzet E., Cohen N., Compagnon P. A., Dewé W., Feinberg M., Laurentie M., Mercier N., Muzard G., Valat L., Rozet E., Harmonization of strategies for the validation of quantitative analytical procedures: A SFSTP proposal-Part III, J. Pharm. Biomed. Anal., 2007, 45, pp 82-96.

[15] Hubert Ph., Nguyen-Huu J. J., Boulanger B., Chapuzet E., Chiap P., Cohen N., Compagnon P. A., Dewe W., Feinberg M., Lallier M., Laurentie M., Mercier N., Muzard G., Nivet C., Valat L., Validation des procédures analytiques quantitatives Harmonisation des démarches, STP Pharma Pratiques, Anal 2003, 13, pp101-138.

[16] Hubert Ph., Nguyen-Huu J. J., Boulanger B., Chapuzet E., Cohen N., Compagnon P.-A., Dewé W., Feinberg M., Laurentie M., Mercier N., Muzard G., Valat L., Rozet E., Harmonization of stratégies for the validation of quantitative analytical procédures: A SFSTP proposal: Part IV. Examples of application, J. Pharm. Biomed. Anal., 2008, 48, pp 760-771. 